\title{
Conocimiento y escritura coloniales en la obra del jesuita Alonso de Ovalle*
}

\author{
Stefanie Massmann ${ }^{* *}$
}

\section{Resumen}

Este artículo se propone contribuir a las discusiones en torno a la construcción del conocimiento sobre el Nuevo Mundo a partir del análisis de una de las más reconocidas obras de la historiografía colonial chilena: Histórica relación del Reino de Chile (1646), del jesuita Alonso de Ovalle. Propongo que el conocimiento sobre Chile desplegado en el texto se modela a partir de dos determinantes: el lugar de enunciación del texto y el uso de fuentes de información o de autoridad. De este modo, se problematiza el hecho de que el criollo jesuita hable sobre su patria desde Europa y para los europeos, es decir, que presente lo familiar ante una mirada ajena.

Palabras clave: Alonso de Ovalle, jesuitas, siglo XVII chileno, poder y conocimiento.

\section{Colonial knowledge and writing in Alonso de Ovalle's work}

\begin{abstract}
This essay aims to contribute to the discussions about knowledge and power in the New World through the study of one of the most famous works in colonial chilean historiography: Alonso de Ovalle's Histórica relación del Reino de Chile (1646). I argue that knowledge about Chile is produced within two principles: the text's locus of enunciation and the use of sources of information or of authority. This issue leads into questioning the author's problematic status as he speaks about his homeland from Europe and for Europeans, presenting his familiar background as if unknown.
\end{abstract}

Key words: Alonso de Ovalle, Jesuits, Chilean XVII Century, Power and Knowledge.

Recibido: 15/07/2018

Aceptado: 09/01/2019

Este trabajo es resultado del simposio “Condiciones de representación”, coordinado por Juan José Adriasola y Luis Valenzuela; una primera versión fue presentada en el XXI congreso de la SOCHEL: "Figuras de lo común. Formas y disensos en los estudios literarios", celebrado en Valparaíso entre el seis y el nueve de noviembre de 2018.

* Chilena. Doctora en Literatura de la Pontificia Universidad Católica de Chile. Académica Universidad Andrés Bello, Santiago, Chile.smassmann@unab.cl 
La Histórica relación del Reino de Chile del jesuita Alonso de Ovalle se terminó de escribir en 1646, el mismo año en que tuvo el privilegio de ser publicada por Francisco Cavallo en Roma, tanto en español como en italiano. El jesuita se hallaba en ese entonces, y desde hacía cuatro años, en Europa, enviado a Roma por la Compañía de Jesús como procurador con el fin de presentar a las autoridades -en especial en la corte de Madrid y en Roma- las peticiones de la recién creada vice provincia de Chile (Hanisch 51).

Alonso de Ovalle había nacido en Santiago en 1603, hijo de un capitán español oriundo de Salamanca, Francisco Rodríguez del Manzano y Ovalle, y de la criolla María Pastene de Astudillo y Lantadilla (Medina, Diccionario 630-31; Hanisch 7-8). Ingresado al noviciado de la Compañía de Jesús a los 15 años, cursó parte de sus estudios en el Colegio Máximo de Córdoba y a su vuelta en Chile, una vez ordenado sacerdote, enseñó filosofía, fue rector del Convictorio de San Francisco Javier, dirigió la Cofradía de Nuestra Señora de Belén de los negros esclavos y misionó en la Ligua y en chacras vecinas a Santiago, además de ejercer la oratoria sagrada (Hanisch 41).

En 1640 fue comisionado para viajar a Europa. El objetivo del viaje era, por una parte, reclutar jesuitas para robustecer el trabajo de la Compañía en Chile, y por otra, conseguir la independencia de la provincia jesuita chilena de la del Perú. En medio de sus viajes por Europa y de su agitada labor diplomática, Ovalle encuentra tiempo para la redacción de su obra, que escribe -como afirma en el prólogo- como reacción al desconocimiento sobre su patria: “[h]abiendo venido del Reino de Chile y hallado en éstos de Europa tan poco conocimiento dél que en muchas partes ni aun sabían su nombre, me hallé obligado a satisfacer al deseo de los que me instaron diese a conocer lo que tan digno era de saberse" (9).

A pesar de que el objetivo declarado de la Histórica relación del Reino de Chile es presentar la labor de los jesuitas del Reino de Chile al público extranjero, la crítica ha preferido centrarse en sus descripciones de la naturaleza, en particular las de los dos primeros libros, en los que podría verse mejor su "sensibilidad de artista" y su "original temperamento" (Bunster xiii) ${ }^{1}$. El mismo Ovalle parece estar consciente de este 
desplazamiento, pues cree necesario justificar la importancia dada a la descripción del Reino, que no se condice con sus propósitos:

aunque el principal motivo que me obligó a tomar la pluma para hacer esta relación fue el dar noticia de los ministerios de las almas en que se ocupa nuestra Compañía de Jesús en el Reino de Chile, pero como éste es el sujeto de estos empleos, no pude menos que hablar dél en primer lugar, y como de cosa desconocida, fue menester dar razón con alguna más extensión de lo que hubiera hecho si hubiera salido a luz su historia o se hallaran algunas relaciones que hablaran de él. (11)

La justificación es por cierto floja y no alcanza a explicar el detalle con que Ovalle da cuenta de su patria, aspecto de la obra que ha sido explicado por la crítica no solo en relación con los propósitos prácticos de la Histórica relación..., sino también con un incipiente discurso criollo de alabanza a la patria (Fischer 35; Prieto, “Alonso de Ovalle...” 207). Esta lectura propone que la descripción del Reino de Chile "funda una retórica de alabanza nacional basada en la afirmación del carácter privilegiado del territorio acaso fundamental a cualquier proyecto de identidad nacional" (Fischer 36). La crítica destaca, así, que Ovalle se configura ante nosotros como "el primero de nuestros autores que describió, con elevado nivel estético, nuestras bellezas naturales, interpretándolas poéticamente, sin dejar de transmitir a cada instante en sus páginas, su hondo amor por su patria" (Bunster xxiii); Francisco Esteve Barba (1964) se expresa de modo similar al resolver que "Ovalle es el primero de los escritores de América que ha sabido contemplar el paisaje en su belleza plena y soberbia" (549)2.

Aunque toda inauguración es siempre sospechosa, vamos a pensar que sí, que Ovalle es, pues, el fundador de todo aquello, pero siendo nuestro, escribe desde allá. Y es este allá en el que quisiera indagar, este desde allá que es también un para los de allá. Lo que interesa aquí es la relación de esta estrecha elite letrada a la que pertenece Ovalle con las

La referencia a un sentimiento criollo no debe entenderse en tanto voluntad de independencia política, sino como la lenta conformación, por parte de los españoles nacidos en América, de una conciencia de su originalidad, identidad y derechos (Lavallé 105). Esta se enmarca en la defensa de los privilegios heredados de sus antepasados conquistadores, siempre amenazados por los intereses de los españoles recién llegados. David Brading (1991) identifica los primeros brotes de protesta criolla en torno a 1590 y describe la constitución de "una conciencia colectiva que separó a los españoles nacidos en el Nuevo Mundo de sus antepasados y primos europeos" que "encontró expresión en la angustia, la nostalgia y el resentimiento" (323). 
estructuras locales y metropolitanas del orden colonial. Para pensar esta relación ambigua y compleja es que recurrimos a Jaime Concha, quien aborda esto en su artículo "La literatura colonial hispano-americana: problemas e hipótesis" (1976). Concha reflexiona sobre la función la poesía gongorina como producción letrada de esta elite y apunta al modo en que esta se transforma, en suelo americano, en un instrumento de alabanza al orden colonial (46). El gesto apologético es la contracara del modo en que la elite se relaciona con la enorme masa de indígenas, negros y mestizos, que ignoran y silencian:

Explotadoras del indio y del negro, ellas [las elites hispanoamericanas] saben inconscientemente que su verdad descansa en el trabajo de esos sub-hombres. No pueden hablar de ello, en consecuencia, ya que tal superioridad no representa una jerarquía ni una autoridad reconfortante. De ahí el silencio de la literatura sobre lo que es el antagonismo principal en la sociedad colonial. Miran entonces a la metrópoli, para reconocer allá un paradigma humano a la medida de sus aspiraciones. Pero esa sociedad los rechaza por distantes y distintos. De este modo, estas clases dominantes resultan a la vez, superiores e inferiores. (Concha 49)

Hay muchas cosas que separan a los poetas gongorinos de nuestro sacerdote jesuita. Sin embargo, la descripción del lugar desde el que hablan los letrados hispanoamericanos es tan relevante para unos como para otros: Ovalle habla del Reino de Chile, pero mira a la metrópoli, y ocupa incómodamente el lugar de "superior e inferior" que describe Concha. El "mirar" a la metrópoli es, en el caso de Ovalle, escribir desde y para ella. Ovalle escribe para que seamos vistos por quienes no nos mirarán: no podemos, entonces, asumirlo simplemente como quien escribe para construir una imagen de nuestra patria. Debemos preguntarnos, en cambio, cuál es la imagen desviada o trunca de nosotros mismos que nos sugiere su texto.

Las manifestaciones de este problema en el texto son variadas, pues Ovalle hace constante referencia a su lugar de enunciación y problematiza algunos aspectos de este. Un primer problema puede identificarse en la actitud de Ovalle respecto del modo en que describe lo conocido/lo nuevo. Como bien ha indicado Mario Ferreccio (2003), los demostrativos (aquí/allí/ ese/aquel) y los verbos de desplazamiento orientado (como ir/venir, llevar/traer) dejan muy en claro que el lugar 
de enunciación del narrador se encuentra en Europa (Ferreccio 648). También se ha destacado el modo en que Ovalle describe a Chile con referencia a, o en comparación, con Europa (Prieto, "Maravillas, monstruos y portentos...” 15; Prieto, “Alonso de Ovalle...” 207-208), muchas veces con el propósito de afirmar la superioridad de Chile frente al viejo continente. La siguiente cita nos proporciona un ejemplo: "Esto es lo que me he podido acordar de los nombres de los pájaros y aves europeas que se hallan en aquel país, a que puedo añadir que es muy singular y raro el que acá he visto por los campos, que no le haya visto en Chile, sin ninguna o con muy poca diferencia" (85). En consonancia con lo que afirma Ferreccio, Ovalle utiliza en esta comparación el mostrativo "aquel” para referirse a Chile. Este tipo de comparaciones es, por razones evidentes, muy frecuente en la historiografía indiana. En el Sumario de la Natural Historia de las Indias (1526) de Gonzalo Fernández de Oviedo, las comparaciones también están a la orden del día, pues son un instrumento útil para describir una gran variedad de animales y vegetales americanos: “El manatí es un pescado de mar de los grandes y mucho mayor que el tiburón en groseza y de luengo, y feo mucho, que parece una de aquellas odrinas grandes en que se lleva mosto en Medina del Campo y Arévalo" (338). La diferencia entre Ovalle y Fernández de Oviedo no está en la figura, sino en el contexto: que el madrileño dé cuenta de las novedades del mundo recién descubierto tomando como referencia lo conocido tanto por él como por sus posibles lectores no debiera sorprendernos; en Ovalle este mismo gesto adquiere, sin embargo, una extrañeza. Ovalle describe lo antiguo, lo conocido, tomando como referencia lo que acaba de conocer, intentando afirmar referentes comunes con unos lectores que ven en él, probablemente, a otro, o, como decía Concha, a un "distante y distinto".

Otro problema surge en relación con las fuentes de información que cita Ovalle. El jesuita pretende informar y convencer a sus lectores sobre las bondades de su patria, y para lograr ese objetivo la información que proporciona debe ser confiable y estar legitimada. Las dificultades para logar aquello son grandes, comenzando con la falta de fuentes de información sobre Chile. En este sentido, el problema de las fuentes para escribir su relación es uno de los puntos más sensibles. Ovalle se queja en su texto de no tener acceso a documentación sobre Chile en Europa. Se declara "confuso" por hallarse sin materiales para trabajar y excusa 
sus posibles faltas argumentando la "poca comodidad y ayuda que puedo haber tenido, por escribir de tan lejos, como lo está Roma de Chile" (9). La forma de suplir la falta de información es acudiendo, entre otros, a cartas que le llegan desde su patria y a su propia memoria.

Lo primero que hay que notar es, por lo tanto, que la Histórica relación... se nutre de fuentes de información heterogéneas que van desde las propias experiencias, los testimonios de otros y cartas, hasta la referencia y cita de fuentes europeas. Las autoridades citadas por Ovalle son a su vez diversas, pues incluyen a españoles que habían viajado a América como José de Acosta, Agustín de Zárate y Alonso de Ercilla, así como a cronistas sin experiencia americana como Antonio de Herrera y Teodoro de Bry.

En segundo lugar, habría que preguntarse en qué medida estas diversas fuentes de información le permiten a Ovalle cumplir con el objetivo de entregar información que sea (y que parezca) confiable. Lo primero que observamos es que la relación y jerarquía entre unas fuentes y otras es confusa. En ocasiones entrega una mayor autoridad a fuentes externas: "Aunque todos los que cito en esta obra son dignos de crédito, son más libres de sospecha los extranjeros en todo lo que toca a las alabanzas que tan repetidamente dan a aquel Reino en sus historias" (10). La aserción de que un panegírico a la patria debe ser sancionado por la autoridad de "los extranjeros" hace eco de la desconfianza hacia los criollos y pone en duda la capacidad del propio Ovalle para dar cuenta de los asuntos americanos. Como veremos más adelante, en otros momentos, Ovalle desacredita la calidad de las noticias de los "extranjeros" y refrenda, en cambio, la de los "nativos". La búsqueda por conseguir credibilidad ante sus lectores lleva al jesuita a echar mano a estrategias diversas y contradictorias que intentaré despejar relevando algunos rasgos de la historiografía indiana.

Uno de los atributos más destacados de la historiografía de indias es la creciente importancia que adquiere el conocimiento asentado en la percepción (Lozano 37) por parte de testigos directos, que privilegia vehículos narrativos como la relación. Este conocimiento empírico comienza a sentar las bases de una nueva forma de saber apartado de los principios de la escolástica, y tiende además a una sistematización e institucionalización por el imperio español (Barrera 46)3. Las relaciones

Antonio Barrera (2006) argumenta que las prácticas de recolección de información empírica fueron ya significativas en el siglo XVI y que la corona española buscó formas de institucionalizar la recolección 
fueron utilizadas más tarde en la elaboración de historias generales que acopiaran grandes cantidades de documentos. Esta fue tarea de los cronistas mayores, historiadores oficiales de Indias que dependían del Consejo de Indias creado en 1571. En 1596 fue nombrado Cronista Mayor Antonio de Herrera, el más prolífico de los historiadores que ocuparon el cargo. Su nombramiento coincide con el momento en el que, según von Ostenfeld-Suske (2014), fue necesario un giro en la historiografía propugnada por la corona española para responder a la leyenda negra que comenzó a articularse entre 1580 y 1592. La defensa de la Corona española frente a estos ataques implicó un intento de legitimar su dominio sobre las colonias a través de una historiografía más imparcial, que interrogaba de una forma más crítica sus fuentes, corroborando, autentificando y probando la información recolectada. El valor de la experiencia comenzó a ser insuficiente y los informantes sospechosos de querer imponer sus intereses por sobre los de la Corona. Podemos confirmar esto con las palabras del mismo Herrera, quien hubo de responder a los críticos que juzgaban "ser cosa vana, y ridiculosa, que trabajen los Autores Españoles en las cosas de las Indias" ("Al licenciado Pablo de Laguna" s/p). En la segunda impresión de Descripción de las Indias Occidentales (1601), Antonio de Herrera se defiende aludiendo a las obligaciones del Cronista Mayor, que son escribir con "mayor autoridad, fundamento, i verdad" en oposición a otros autores, muchas veces testigos directos de los hechos, que no son fiables ${ }^{4}$. Cuando Ovalle otorga más crédito a los extranjeros está poniendo, por sobre el valor de la experiencia, esta mayor imparcialidad de la que se jacta Herrera, autor citado en más de una ocasión por el jesuita. Hay aquí una coincidencia con la cronística oficial que, sin embargo, y como he adelantado, no es consistente. Un poco más adelante Ovalle declara lo siguiente, tras citar a Antonio de Herrera, Teodoro de Bry y a los hermanos Nodal:

Pero para qué me canso en testiguar con testigos que solo vieron este Reino por de fuera, cuando consta a los que están dentro y lo han visto, la gran riqueza que han sacado los españoles de estas minas, que es tanta, que oí decir a mis mayores que

de la información a través de la casa de Contratación, del Consejo de Indias, de la elaboración de mapas y cuestionarios.

Se discute esta polémica entre Juan Bautista Ramusio y Antonio de Herrera en mi artículo "De sur a norte: geopolíticas de conocimiento en diarios de viaje y crónica oficiales de Indias”, Anales de Literatura Chilena, no. 24, 2015, pp. 17-34. 
en los banquetes y bodas ponían tal vez en los saleros, en lugar de sal, oro en polvo, y que cuando barrían las casas, hallaban los muchachos pepitas de oro en la basura, lavándola en la acequia. (35)

Después de apoyarse en el prestigio de historiadores más "imparciales", parece que Ovalle vuelve a acudir a la autoridad del testimonio. Este es válido no solo porque transmite lo visto y lo vivido, sino porque transmite la experiencia de los criollos, pues Ovalle insiste aquí en que se trata de los que han visto desde "dentro" y no los que han visto "por de fuera", los viajeros o quienes solo conocen a través de los relatos de terceros. En Ovalle encontramos en varias partes del texto los términos y expresiones que estamos acostumbrados a leer en la historiografía indiana: fui testigo, lo vi, lo vivín. Pero si leemos nuevamente el pasaje recién citado veremos que en este caso -a pesar de las apariencias- no hay aquí exactamente una reivindicación del propio testimonio. El privilegio epistemológico del testigo manifestado en otras partes del texto en la insistencia de los "me acuerdo" se diluye aquí por partida doble en el colectivo de "oí decir a mis mayores" (que también se encuentra en otras partes de la obra: "oyó uno de los nuestros" (45); “oí contar a muchos" (53)) y también en la modulación probabilística del "tal vez". En suma, en esta cita el testimonio de Ovalle no es propio y tiene más la forma de una posibilidad que de una certeza. Ovalle no acude solamente a su propia experiencia, sino que valida también, con bastante frecuencia, la experiencia de otros transmitida oralmente, o bien, lo que incluso puede calificarse como un rumor, pues no hay siquiera atribución de la identidad de quien da el testimonio: "oí contar a muchos varias veces", dice, por ejemplo, "que si estando ya sentados a la mesa se les antojaba una trucha fresca, no tenían sino enviar a pescarla, y que antes de levantarse se la traían aderezada como gustaban" (53).

\footnotetext{
Algunos ejemplos pueden ilustrar el modo en que Ovalle hace referencia a su calidad de testigo y conocedor: "Esto es lo que este autor [Antonio de Herrera], y otros que tratan de las cosas de las Indias, cuentan de la cordillera. Yo diré ahora lo que sé y he visto de ella" (40). Más adelante, al describir un río que puede observarse desde un precipicio en la cordillera: "Yo he llegado al bordo de esta puente, y mirando para abajo (aunque con gran pavor, porque pone grima tan inmensa altura, y no he visto jamás despeñadero más formidable), no sólo no oí rumor ninguno, pero pareció de allí todo el río un pequeño arroyo, que apenas le divisaba con la vista". Esta descripción culmina con una reflexión sobre los límites del conocimiento del testigo (se basa en la experiencia, que es limitada): "Esto es lo que se ve por este camino, atravesando por esta parte la cordillera; pero las demás cosas que habrá que ver en todo lo restante de la inmensa mole, ¿quién habrá que lo cuente?, ¿quién lo sabe? No dudo que habrá otros que sepan muchas más cosas, que yo aquí no cuento, sino lo que he visto, que siempre será lo menos" (49).
} 
¿Qué nos dice este uso tan particular de las fuentes sobre el lugar de enunciación de Ovalle? Nos dice que para convencer al lector europeo de las virtudes de su patria debe ocupar, por un lado, el lugar tradicional del "informante" nativo (Bauer 4), del testigo de vista que provee información incompleta, pero verdadera, que luego ha de ser elaborada en el seno de la metrópoli. Pero la obra de Ovalle no es una relación de su propia experiencia, sino un intento ambicioso por escribir la primera historia natural, moral y sagrada del Reino de Chile, esfuerzo que implica recabar información mucho más allá de la propia experiencia. Los modelos de Alonso de Ovalle en el ámbito de la crónica de Indias son, sin duda, Gonzalo Fernández de Oviedo y -más de cerca- el también jesuita José de Acosta. El primero elige organizar la enorme información sobre las Indias siguiendo en parte el modelo de Plinio (la organización temática del mundo natural), aunque le agrega a este una perspectiva histórica que configura el despliegue de la monarquía nacional española (Carrillo 2927). Se trata de un formato que intenta "producir una visión completa y estructurada de la realidad americana" (Carrillo 2930), cuyo orden está articulado con la noción de que la Monarquía Católica es una entidad capaz de producir ese orden o, podemos decir, de aglutinar esos fenómenos aparentemente dispersos (Carrillo 2931). El segundo modelo que Ovalle sigue es la Historia natural y moral de las Indias (1590) de José de Acosta, que tuvo un gran éxito editorial. Esta obra separa más claramente el ámbito "natural" (descripción de animales, vegetales, minerales) y el "moral”, (referido a la historia humana) ${ }^{6}$. Estas dos obras reivindicaban la observación directa -no solo del mismo autor, sino de numerosos testigos o informantes- como fuente de información (Ayala 33) para articular obras de gran alcance y pretensión globalizadora. También se trata de obras autorizadas y que tuvieron una importante difusión y prestigio ${ }^{7}$.

Ovalle continúa con esta tradición y organiza su libro de forma sistemática, para lo cual aborda en los primeros libros la descripción

\footnotetext{
En el caso de Acosta, la historia moral es más que nada historia de las costumbres de los americanos, o "etnografía", por sobre la historia de la conquista española.

Esta es especialmente notable en el caso de la Historia natural y moral de las Indias de Acosta, que se publicó en Sevilla en 1590, al año siguiente en Barcelona y en 1608 en Madrid. Traducida además a diversos idiomas y publicada en toda Europa, fue "una obra de gran éxito, precisamente accesible al público medio (no al popular, seguramente)” (del Pino-Díaz XXVIII). En el caso de Gonzalo Fernández de Oviedo, su Sumario de la natural y general historia de las Indias tuvo varias ediciones y traducciones, no así la Historia Natural y general de las Indias, pues solo la primera parte fue publicada en vida del autor.
} 
de la dimensión "natural" y luego la "moral", incluyendo la labor evangelizadora de la Compañía. Su alcance geográfico es menor, pues no hace una historia de las Indias, sino de un territorio más acotado, pero sigue siendo general en cuanto abarca todas las dimensiones del Reino de Chile. Alonso de Ovalle apuesta al prestigio de una obra de estas características, en la que los acontecimientos o hechos no siguen a la experiencia del autor, sino que están determinadas por una estructura preestablecida. Si bien ocupa el lugar del informante, Ovalle se configura sobre todo como un historiador que eleva un juicio sobre aquello que parece creíble o no. Se arroga el privilegio de autorizar historias, anécdotas e incluso rumores como fuentes creíbles de información sobre las maravillas de su patria, por lo que otorga amplio crédito a fuentes orales, anónimas y colectivas. Este es un gesto de atrevimiento, sin duda, aunque también resulta precario: si bien Ovalle se emancipa de su posición de testigo y utiliza por igual fuentes "autorizadas" e incluso "oficiales", y relatos orales de diverso origen, la violencia que está implicada en el gesto de citar a autores metropolitanos sin experiencia en las Indias devela su difícil postura como escritor americano.

Volvamos ahora también a las descripciones de la naturaleza tan extraordinarias de Ovalle: en ellas no hay solo un lenguaje cuidado y preciso, no hay solo una expresión rica y original: hay también una mirada sorprendida, inaugural, sobre la naturaleza de Chile, una que se mira con ojos ajenos, una que se observa desde lejos como un espacio extraordinario, exótico, mágico. Ovalle escribe desde allá, y para los de allá construye una imagen nuestra que nosotros no oiremos, o más bien, que oiremos desde lejos, como extrañándonos de nuestra propia condición. De alguna manera, esta imagen sorprendida colabora también con la consolidación de un discurso colonialista. Ovalle hace constante referencia a las ingentes riquezas del Reino: el oro en los saleros, el oro olvidado en el suelo. Estas riquezas cumplen el requisito de no estar explotadas, de ser infravaloradas y desperdiciadas, lo que no solo autoriza, sino que convierte su explotación por parte de los colonizadores casi en un deber. La referencia al oro que queda es el cumplimiento de una utopía, de la utopía del conquistador español. Ovalle narra aquí una historia transmitida oralmente, un pequeño mito local, una breve anécdota que actualiza la idea de El Dorado o de la Ciudad de los Césares. Las tierras americanas como objeto de deseo, como depositarias de tesoros guardados para los españoles - "son tantas minas en este Reino, 
que más valía llamar esta tierra una plancha o lámina de oro, que poner a contar sus minas, por ser inumerables" (34), dirá Ovalle- no son ya el sueño de esos otros, sino que se han convertido en nuestro propio sueño. $\mathrm{O}$ al menos así parece.

\section{Referencias bibliográficas}

Acosta, José de. Historia natural y moral de las Indias. Ed. Edmundo O'Gorman. México D.F., FCE, 2006.

Ayala, María de la Luz. "La historia natural en el siglo XVI: Oviedo, Acosta y Hernández”. Estudios del Hombre, no. 20, 2005, pp. 19-38.

Barrera, Antonio. "Empire and Knowledge: Reporting from de New World”. Colonial Latin American Review, vol.1, no. 15, 2006, pp. 39-54.

Bauer, Ralph. The Cultural Geography of Colonial American Literatures. Empire, Travel, Modernity. New York, Cambridge University Press, 2003.

Brading, David A. Orbe indiano: De la monarquía católica a la república criolla, 1492- 1867. Trad. Juan José Urtilla. México, D.F., FCE, 1991.

Bunster, César. "Prólogo a la segunda edición de la Histórica Relación del Reino de Chile del Padre Alonso de Ovalle. Algo acerca del trabajo realizado y algunas reflexiones sobre el valor literario de la obra". Alonso de Ovalle. Histórica Relación del Reino de Chile. Ed. Mario Ferreccio. Santiago de Chile, Pehuén, 2003.

Carrillo, Jesús. “Gonzalo Fernández de Oviedo, Plinio y la génesis de la historia natural y moral". Science and cultural diversity: proceedings of the XXIst International Congress of History of Science. Ed. Juan José Saldaña. México D.F., UNAM, 2003.

Concha, Jaime. "La literatura colonial hispano-americana: problemas e hipótesis". Neohelicon, vol. IV, no. 1-2, 1976, pp. 31-50.

Del Pino-Díaz, Fermín. "Estudio introductorio". Historia Natural y Moral de las Indias. Josef de Acosta. Ed. Crítica de Fermín del Pino-Díaz. Madrid, Consejo Superior de Investigaciones Científicas, 2008.

Esteve Barba, Francisco. Historiografía Indiana. Madrid, Gredos, 1964. 
Ferreccio, Mario. "Presupuestos para una edición crítica de la histórica relación del Reino de Chile de Alonso de Ovalle”. Alonso de Ovalle. Histórica Relación del Reino de Chile. Ed. Mario Ferreccio. Santiago de Chile, Pehuén, 2003.

Fischer, María Luisa. "Para leer la historia eclesiástica: El caso de la Histórica Relación del Reino de Chile (1646) del Padre Alonso Ovalle". Taller de Letras, no. 31, 2002, pp. 33-43.

Hanisch, Walter. El historiador Alonso de Ovalle. Caracas, Universidad Católica Andrés Bello, 1976.

Herrera, Antonio de. “Al licenciado Pablo Laguna”. Descripción de las Indias Occidentales [1601]. Madrid, Oficina Real de Nicolás Rodríguez Franco, 1725.

Lavallé, Bernard. Las Promesas ambiguas: ensayos sobre el criollismo colonial en los Andes. Lima, Pontificia Universidad Católica del Perú, 1993.

Lozano, Jorge. El discurso histórico. Madrid, Alianza, 1994.

Massmann, Stefanie. “De sur a norte: geopolíticas del conocimiento en diarios de viaje y crónicas oficiales de Indias". Anales de Literatura Chilena, no. 24, 2015, pp. 17-34.

Medina, José Toribio. Diccionario biográfico colonial de Chile. Santiago de Chile, Imprenta Elzeviriana, 1906.

Ovalle, Alonso de. Histórica Relación del Reino de Chile. Ed. Mario Ferreccio. Santiago de Chile, Pehuén, 2003.

Oviedo, Gonzalo Fernández de. Sumario de la Natural Historia de las Indias. Ed. Álvaro Baraibar. Madrid/Frankfurt, Iberoamericana Vervuert, 2010.

Prieto, Andrés. "Maravillas, monstruos y portentos: la naturaleza chilena en la Histórica relación del Reyno de Chile (1646), de Alonso de Ovalle". Taller de Letras, no. 47, 2010, pp. 9-27.

“Alonso de Ovalle y la Histórica relación del Reino de Chile (1646)". Historia crítica de la Literatura chilena. Vol. I. La era colonial. Coordinadores Generales Grínor Rojo y Carol Arcos. Coordinadora Vol. I. Stefanie Massmann. Santiago, Lom, 2017.

von Ostenfeld-Suske, Kira Kalina. Official Historiography, Political Legitimacy, Historical Methodology, and Royal and Imperial 
Authority in Spain under Phillip II, 1580-99. Tesis para optar al grado de Doctora en Filosofía. Columbia University, 2014. 